\title{
CTP BORU ÜRETIMM ATIĞI İLAVELİ PVC MATRİKSLİ KOMPOZİT MALZEMELERİN MEKANİK ÖZELLİKLERİNINN İNCELENMESİ
}

\author{
Arzu ÖZÜYAĞLI ${ }^{1}$, Cem MEHMETALİOĞLU ${ }^{2}$, Murat ÖZSOY $^{3}$, Akın AKINCI $^{3}$ \\ ${ }^{1}$ Asaş Alüminyum Sanayi ve Ticaret A.Ş. İstiklal Mah. Kışla Alanı Mevkii Küçücek Beldesi, Akyazı, Sakarya \\ ${ }^{2}$ Makine Mühendisliği Bölümü, Sakarya Üniversitesi, Sakarya \\ ${ }^{3}$ Metalurji ve Malzeme Mühendisliği Bölümü, Sakarya Üniversitesi, Sakarya

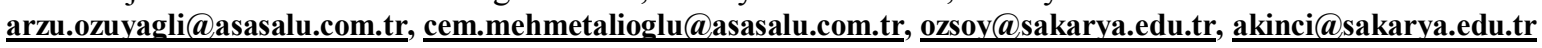

(Geliş/Received: 21.06.2015; Kabul/Accepted: 28.02.2016)

\section{ÖZET}

Bu çalışmada, Polivinilklorür (PVC) boru üretiminde geleneksel olarak kullanılan $\mathrm{CaCO}_{3}$ dolgu malzemesi yerine, cam elyaf takviyeli polyester (CTP) boru üretiminde sulu kesim sırasında çıkan sanayi atığı kullanıldı. Atık; silisyum dioksit $\left(\mathrm{SiO}_{2}\right)$, cam elyaf ve polyester reçine içermektedir. Sulu çamur halinde filtre presten çıkan atık fabrikadan alındıktan sonra kurutma öğütme ve eleme işlemleri uygulanarak, toz formuna getirildi. Numuneler PVC, CTP atık tozu ve prosese yardımcı maddeler mikserde karıştırılarak ekstrüzyon yöntemi ile profil şeklinde üretildi. Atık toz, PVC'ye ağırlıkça \%5-\%70 oranlarında dolgu malzemesi olarak kullanıldı. Karşılaştırma yapılabilmesi açısından $\mathrm{CaCO}_{3}$ katkılı ve katkısız PVC numuneleri de aynı şartlarda üretildi. Tüm PVC matrisli kompozit numunelere yoğunluk, sertlik, çekme mukavemeti, eğme mukavemeti ve darbe dayanımı deneyleri yapılarak, kırık yüzeylerden taramalı elektron mikroskop (SEM) görüntüleri ve optik görüntüler alındı. PVC üretiminde geleneksel olarak kullanılan kalsiyum karbonat dolgu yerine CTP atık toz dolgu kullanılarak daha yüksek sertlik, eğme mukavemeti ve çekme mukavemeti değerleri elde edildi. $\mathrm{CaCO}_{3}$ dolgulu numunenin darbe dayanımının ise daha yüksek olduğu belirlendi. Atık katkısı ile daha düşük yoğunluk değerine sahip kompozit malzeme üretimi gerçekleştirildi.

Anahtar Kelimeler: CTP, PVC, atık, $\mathrm{CaCO}_{3}$, mekanik özellikler

\section{INVESTIGATION OF MECHANICAL PROPERTIES OF GFRP PIPE PRODUCTION WASTE FILLED PVC MATRIX COMPOSITES}

\begin{abstract}
In this study, waste powder output of wet cutting stage in GFRP pipe production was used instead of $\mathrm{CaCO}_{3}$ filler traditionally used in PVC pipe production. Waste includes silicon dioxide $\left(\mathrm{SiO}_{2}\right)$, glass fibre and polyester resin. Slurry, output of the filtre press was dried, milled, sieved and powdered respectively. Waste powder and aid materials in the process were mixed by an extruder to produce samples. Waste powder was used as a filler material in the PVC by weight ratio of $5 \%-70 \% . \mathrm{CaCO}_{3}$ filled and pure $\mathrm{PVC}$ samples were produced in the same conditions to make comparison. The properties of all the PVC matrix composite samples were investigated by density, hardness, tensile strength, bending strength and impact resistance tests. Also scanning electron microscope and optic images were obtained from the cracked surfaces. Higher hardness, flexure and tensile strength values were obtained by using GFRP waste powder filler instead of calcium carbonate filler traditionally used in PVC production. The experimental results showed that $\mathrm{CaCO}_{3}$ filled samples had better impact strength. Lower density composite material production was performed by GFRP waste powder filler.
\end{abstract}

Keywords: GFRP, PVC, waste, $\mathrm{CaCO}_{3}$, mechanical properties

\section{GİRIŞ (INTRODUCTION)}

Polimerik ve polimer esaslı kompozit malzemelerin çeşitli endüstri dallarında kullanım oranı her geçen yıl hızla artmaktadır. Polimer matrisli kompozit malzemeler, geleneksel malzemelere göre hafiflik, düşük maliyet ve üstün mekanik, termal, kimyasal ve elektriksel özellikleri sebebiyle tercih edilmektedir. Polipropilen (PP), polietilen (PE), polivinilklorür (PVC), akrilonitrilbütadienstiren (ABS), polikarbonat 
(PC), polimetilmetakrilat (PMMA) ve polistiren (PS) gibi termoplastik esaslı matris malzemeleri düşük fiyatları, kolay üretilebilmeleri ve geri dönüştürülebilir olmaları açısından, polyester, epoksi ve poliüretan gibi termoset esaslı matris malzemelerinden daha fazla miktarlarda kullanılmaktadır [1]. PVC, hem dünyada hem de Türkiye'de birçok ürünün temelini oluşturmaktadır. Yalıtım amacıyla kablo yüzeyinden, inşaat sektöründe kullanılan borulara kadar oldukça geniş bir sektör aralığında kullanılmaktadır. PVC, düşük maliyet, esneklik, hafiflik, nakliye, yerleştirme kolaylığı ve dayanıklılık gibi özellikleri sayesinde tüm dünyada atık su boruların da yaygın olarak kullanılmaktadır [26]. PVC malzemenin monomerinde bulunan klor atomları, karbon atomlarına kovalent bağlarla bağlı olup, bu monomerlerden oluşan zincirler arasında çift kutuplu güçlü etkileşimlerin sonucunda sert bir polimerik malzeme ortaya çıkmaktadır [5-8]. PVC, asit ve bazların etkilerine karşı dayanıklı bir polimer olup yoğunluğu 1,39-1,42 $\mathrm{g} / \mathrm{cm}^{3}$ arasında değişmektedir, aynı zamanda malzemenin yoğunluğu sadece polimere değil dolgu maddelerine de bağlı olmaktadır [7-9]. Partikül dolgu/takviye malzemeleri, genellikle maliyet ucuzlatmak için polimerik malzemelerde kullanılsa da, üstün özellikli partiküllerin kullanımıyla, üretilen kompozit malzemelerin mekanik, termal, elektriksel ve kimyasal özellikleri geliştirilebilmektedir. Örneğin cam küre, cam bilye gibi partiküllerin ilavesiyle de aşınmaya dirençli polimerik kompozitler üretilebilmektedir [10-12]. $\mathrm{SiO}_{2}$ dolgulu PVC düşük yoğunluğu ile ev gereçleri, yapı malzemeleri, otomobil sektörü ve elektrik endüstrisinde kullanılmaktadır. $\mathrm{CaCO}_{3}$ dolgusu günümüzde yaygın olarak inşaat malzemeleri, elektrik kablosu kaplamaları, gıda sektörü, otomobil sektörü ve yapı malzemelerinde kullanılmaktadır [4-12]. $\mathrm{SiO}_{2}$ ve cam fiber dolguları; mekanik dayanımı özellikle aşınma dayanımını arttırırlar, boyut kararlığı sağlarlar ve bu nedenle özellikle hassas ölçülerin eldesi ve uzun süre çalışacak plastik ürünlerin yapımında kullanılmaktadır. Ayrıca 1sıl iletkenliği düşürmektedir. $\mathrm{CaCO}_{3}$ dolgusu gibi ürün maliyetini düşüren katkı maddeleri aşırı oranda kullanılmadıkça mekanik dayanımı arttırmakta ve 1sı iletkenliğini düşürmektedir [13]. Zhu ve arkadaşları PVC'ye $\mathrm{SiO}_{2}$ katkısının çekme mukavemetini ve 1sısal kararlılığ arttırdığını gözlemlemişlerdir [14]. Bu çalışmada sürekli elyaf sarma prosesi ile polyester, cam elyaf ve kum $\left(\mathrm{SiO}_{2}\right)$ kullanarak CTP boru üretimi sirasında çıkan kesme atıklarının, PVC kompozit üretiminde $\mathrm{CaCO}_{3}$ dolgusu yerine dolgu malzemesi olarak kullanımı ile üretilen malzemelerin mekanik özellikleri araştırıldı. İngiltere'de her yıl 55.000 ton cam fiber takviyeli üretim atığı çıkmakta ve sektörün gelişmesi ile bu oranın her yıl $\% 10$ oranında artması beklenmektedir. Bu atık miktarı Avrupa'da ortaya çıkan benzer atıkların sadece \%18'dir [15]. Cam fiber, silis kumu ve reçine içerikli atık doğaya bırakıldığında çevre açısından tehdit oluşturmasına rağmen PVC kompozit malzeme üretiminde kullanılması ile bu sorunun ortadan kalkacağı düşünülmektedir. Kullanılması düşünülen atık, dolgu/takviye malzemesi olarak PVC sektörüne katkı sağlayacaktır. Atık ile üretilecek ürünlerin sektörde kullanılması ile az maliyetli daha kaliteli ürünler üretilmesi beklenmektedir. CTP kesme atığ 1 sulu kek halinde Subor Boru San. ve Tic. A.Ş.'den alınarak PVC içerisine farklı oranlarda ilave edildi. Karşılaştırma yapılabilmesi açısından kalsit dolgulu ve dolgusuz saf PVC numuneler de üretildi. Üretilen numunelere standartlara uygun olarak yoğunluk, sertlik, çekme, eğme ve darbe deneyleri yapıldıktan sonra optik ve SEM görüntüleri alındı.

\section{DENEYSEL YÖNTEMLER (EXPERIMENTAL METHODS)}

CTP kesme atığı filtre pres sisteminden sulu kek halinde çıkmaktadır. Atık sulu kesme çamuru kek halinde Subor Boru San. ve Tic. A.Ş.' den alınarak etüvde 48 saat boyunca $90^{\circ} \mathrm{C}$ ' de kurutuldu. Atığa kurutulmadan önce ve kurutulduktan sonra nem tayini yapıldı. Kurutulan atık mekanik mikserde karıştırıldıktan sonra $500 \mu \mathrm{m}$ boyutundaki titreşimli elekte 10 dakika elenerek boyut sınıflandırılması yapıldı. Numune üretiminde, matris malzemesi olarak tane boyutu 40 mikron altı olan PVC kullanıldı. Toz formundaki PVC, SINTAŞ Plastik ve Metal San. Tic. A.Ş. 'den, stabilizatör olarak kullanılan $\mathrm{Ca} / \mathrm{Zn}$ ve $\mathrm{Pb}$ bazlı metal bileşiği olan akropan, Akdeniz Kimya San. Tic. A.Ş. 'den ve Rijit PVC basınçlı boru üretiminde beyaz renk verici olarak kullanılan titanyum dioksit $\left(\mathrm{TiO}_{2}\right)$, Sayman Kimyevi Maddeler San. ve Tic. A. Ş. 'den temin edildi. PVC içerisine farklı oranlarda (\%5-\%5-\%10-\%15-\%20-\%25-\%30\%35-\%40-\%45-\%50-\%60-\%70) CTP kesme atığ1 ilave edildi. Karşılaştırma yapabilmek için kalsit dolgulu ve dolgusuz saf PVC numuneler de üretildi. Saf PVC üretimi için 100 gr. PVC'ye, \%3,5 akropan, $\% 1$ titan eklenerek karışım hazırlandı. Atık su borularında $\% 30$ kalsit katkısı kullanıldığı bilinmektedir [16]. Dolayısıyla atık su borularına benzer üretim yapmak amaciyla PVC üretiminde belirlenen karışıma, \%30 kalsit ilavesi yapılarak hazırlanan karıșımlar, mikserde $30 \mathrm{dk}$. karıștırıldıktan sonra 24 saat dinlendirilerek laboratuvar tipi çift vidalı ekstrüzyon hattına beslendi. Uygun sıcaklıkları tespit etmek için deneme yanılma yöntemi kullanıldı. Ekstrüzyon hattından, dikdörtgen kesitli profil şeklinde çıkan ürün bilgisayar kontrollü dik işleme merkezinde çekme numunesi için ASTM D638, eğme numunesi için ASTM D790, darbe numunesi için ASTM D4812 standartlarında belirtilen ölçülerde numuneler haline getirildi. Üretilen numunelere, yoğunluk, shore D sertlik, çekme, üç nokta eğme ve darbe deneyleri yapılarak optik mikroskop ve taramalı elektron mikroskopu görüntüsü (SEM) görüntüleri alınd1. 


\subsection{Nem Testi (Moisture Test)}

ASTM D 6980-12 standardına göre numunenin başlangıç ağırlığı kaydedildi, sonra numune kurutuldu ve bir yandan da entegre bir terazi kullanılarak sürekli olarak numune ağırlığı kaydedildi. Toplam ağırlık kaybı nem oranı olarak yorumland 1 [17]. Metler Toledo HX204 model nem tayini cihazında atığın kurutulmadan önce ve kurutulduktan sonra nem tayini yapild1.

\subsection{Yoğunluk Deneyi (Density Experiment)}

Yoğunluk değerleri için öncelikle numunelerin havada ağırlıkları ölçüldü. Daha sonra cam beher içerisindeki saf suyun içerisine konulan numunelerin yoğunlukları otomatik olarak hesaplandı [18]. Yoğunluk testi ASTM D792 standardına göre yapılmıştır [19]. Üretilen kompozit malzemelerin yoğunluk değerleri RADWAG AS 220/C/2 marka yoğunluk kitiyle ölçüldü.

\subsection{Sertlik Deneyi (Hardness Experiment)}

Çalışmada, sertlik ölçümleri sert kauçuk, termoplastik elastomerler, sert plastikler ve sert termoplastikler için tercih edilen Shore D ölçüm cihazı kullanılarak, ASTM D2240 standardına uygun olarak gerçekleştirildi [20]. Standarda göre $15 \times 120 \mathrm{~mm}^{2}$ boyutunda numuneler hazırlanarak ve her numuneden 10 ölçüm alınarak, ortalamaları hesaplandı.

\section{4 Çekme Deneyi (Tensile Experiment)}

Çekme deneyi standartlara göre hazırlanmış deney numunesinin tek eksende, belirli bir hizla ve sabit sıcaklıkta kopuncaya kadar çekilmesidir [21]. Çekme deneyleri Zwick/Roell Z020 cihazında oda sicaklığında, ASTM D638 standardına uygun olarak gerçekleştirildi. Her çekme testi en az 5 kere tekrarlanmış olup, ortalama değer çekme mukavemeti olarak alınd1 [22].

\section{5 Üç Nokta Eğme Deneyi (Three Point Flexural Experiment)}

Üç nokta eğme deneyleri Zwick/Roell Z050 cihazında oda sicaklığında ASTM D 790 standardına uygun olarak gerçekleştirildi. ASTM D790 standardına göre numune $12,7 \mathrm{~mm}$ genişlik, $127 \mathrm{~mm}$ uzunluk ve 3,2 mm kalınlık ölçülerine sahip olmalıdır [23]. Her deney en az $5 \mathrm{kez}$ tekrarlanmış olup ortalama değerler alindi.

\subsection{Darbe Deneyi (Impact Experiment)}

Malzemenin dinamik yüklere karşı kırılma enerjisini belirlemek için yapılan bir deneydir. Numunelere ASTM D4812 standardına göre çentiksiz izod darbe deneyi yapıldı. ASTM D4812 standardına göre numune $12,7 \mathrm{~mm}$ genişlik, $63,5 \mathrm{~mm}$ uzunluk ve 3,2 mm kalınlık ölçülerine sahip olmalıdır [24]. Her deney $10 \mathrm{kez}$ tekrarlanmış olup ortalama değer kırılma enerjisi olarak verildi.

\subsection{DTA-TG Analizi (DTA-TG Analysis)}

Numunelerden seramik alümina $\left(\mathrm{Al}_{2} \mathrm{O}_{3}\right)$ krozelere sığacak şekilde parçalar alınmış ve krozeye konulmuştur. Tüm numunelere DTA-TG analizi NETZSCH marka STA 449F1 model cihazında, $0^{\circ} \mathrm{C}$ ile $1000^{\circ} \mathrm{C}$ sicaklıklar arasında $\operatorname{azot}(\mathrm{N})$ ortamında yapılmıştır

\section{BULGULAR VE TARTIŞMA (RESULTS AND DISCUSSION)}

\subsection{Atığın İçerik Analizi (Content Analysis of Waste)}

Subor Boru San. ve Tic. A.Ş.'den temin edilen atı̆̆ın X-Işını Difraktometresi (XRD) analizi Şekil 1'de verilmektedir. Temin edilen atık yoğun olarak kum ve cam fiberden oluşmaktadır. Buna bağlı olarak analizde kuvarz ve silisyum dioksit pikleri görülmektedir.

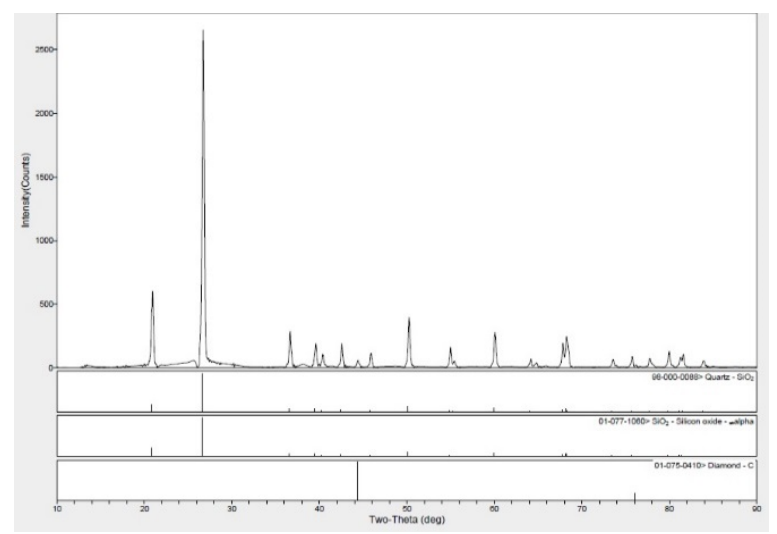

Şekil 1. Atığın XRD analizi (XRD analysis of the waste)

Şekil 1' den görüldüğü üzere, CTP boruda dolgu malzemesi olarak kullanılan kum ve takviye malzemesi olarak kullanılan cam fiberin içeriğinde bulunan kuvarz (quartz) ve silisyum dioksit $\left(\mathrm{SiO}_{2}\right)$ piklerinin, belirgin 2 teta açılarının sırasıyla 20,9-26,7 -36,6-39,5-40,3-42,5-46,5-50,1-67,8 derece olduğu tespit edilmiştir. XRD analizinde 44,1-77,0 derecelere sahip pikler ile tespit edilen elmas (diamond) ise boruların kesilmesi, kanal açılması ve taşlanması sırasında kullanılan disklerin kaplamasında bulunan aşındırıcı malzemenin kesme atığı ile birlikte filtre preste toplanmasından kaynaklanmaktadır.

\subsection{Nem Testi (Moisture Test)}

Kek halindeki atığa yapılan nem tayini sonucunda atığın \%31 nemli olduğu görüldü. Atık etüvde kurutulduktan sonra numuneye yapılan nem tayini sonucunda ise atığın $\% 0,189$ nem ihtiva ettiği belirlendi.

\subsection{Yoğunluk Deneyi (Density Experiment)}

Kalsit, farklı oranlarda kesme atığı içeren PVC matrisli kompozitlerin ve saf PVC numunenin yoğunluk deneyi sonuçlarını içeren grafik Şekil 2'de verilmektedir. Üretilen saf PVC yoğunluğu 1,40 
$\mathrm{g} / \mathrm{cm}^{3}$ tespit edildi. Mengenoğlu ve arkadaşları PVC yoğunluğunu $1,35 \mathrm{~g} / \mathrm{cm}^{3}$ olarak bulmuşlardır [25]. En yüksek yoğunluk değeri kalsit katkılı numunede görülmektedir. PVC' ye eklenen atık oranı arttıkça numune yoğunluğu artmaktadır, buna rağmen tüm atık katkılı yoğunluk değerleri kalsit katkılı numuneden daha düşük çıkmaktadır.

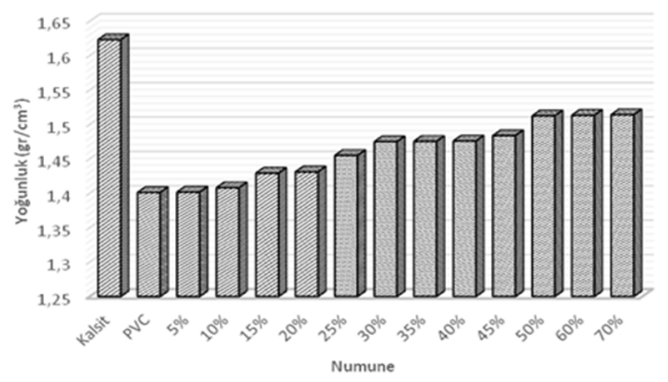

Şekil 2. Farklı PVC kompozitler için yoğunluk değerleri (Density values for different PVC composites)

\subsection{Sertlik Deneyi (Hardness Experiment)}

Kalsit, farklı oranlarda kesme atığ 1 içeren PVC matrisli kompozitlerin ve saf PVC numunenin Shore D sertlik ölçümleri Şekil 3'de verilmektedir.

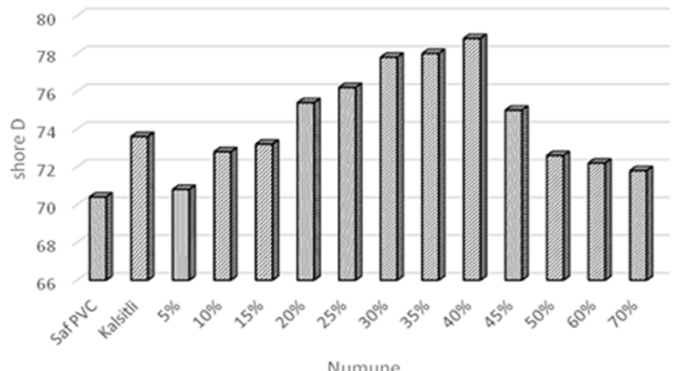

Şekil 3. Farklı PVC kompozitler için Shore D sertlik değerleri(Shore D Hardness values for different PVC composites )

Saf PVC sertlik değeri 70,4 Shore D, \%40 atık katkılı PVC kompozit numunenin sertlik değeri ise 78,8 Shore D bulundu. PVC' ye eklenen atık oranı arttıkça $\% 40$ atık katkılı numuneye kadar sertlik artmakta daha sonra ise sertlikte düşüş görülmektedir. En yüksek sertlik değeri ise $\% 40$ atık katkılı numunede gözlemlenmektedir.

3.5 Çekme Deneyi, Kırık Yüzeyi Mikroyapıları (Tensile Experiment, Microstructure of Tensile Fractured Surface)

Kalsit, farklı oranlarda kesme atığı içeren PVC matrisli kompozitlerin ve saf PVC numunenin çekme deneyi sonucunda elde edilen çekme mukavemeti kopma mukavemeti ve kopma uzaması değerleri Şekil 4'de verilmektedir. Saf PVC için kopma mukavemeti 30,2 MPa olarak bulundu. Mengenoğlu ve arkadaşları PVC kopma mukavemetini 32,2 $\mathrm{MPa}$ olarak bulmuşlardır [25]. Saf PVC çekme mukavemeti 46,8 $\mathrm{MPa}$ olarak bulunmuştur. Chen ve arkadaşları PVC çekme mukavemetini $40 \mathrm{MPa}$ olarak bulmuşlardır
[26]. Zeng ve arkadaşları ise PVC çekme mukavemetini 41,3 MPa olarak bulmuşlardır [27]. En düşük çekme ve kopma mukavemeti kalsit dolgulu numunede görülmüştür. PVC ye eklenen atık oranı arttıkça genel olarak çekme ve kopma mukavemetinde düşüş görülmüştür. \%35 atık katkılı numunede ise artış görülmüştür. $\mathrm{Bu}$ durumun numune üretiminden kaynaklandığı düşünülmektedir. En yüksek \% kopma uzaması saf PVC numunede ve en düşük \% kopma uzaması kalsit katkılı numunede görülmüștür. Çekme numunelerinin kırık yüzeylerinden SEM ve optik görüntüler alınmıştır. Tüm numunelerin kırık yüzeylerinin optik görüntüleri Huvitz marka dijital 3D optik mikroskop ile alınmıştır. Yüksek çekme mukavemetine sahip olan Saf PVC, kalsit dolgulu PVC ve \%5-\%10-\%15 ve \%35 kesme atığ1 katkılı numunelerin görüntüleri Şekil 5'de verilmektedir. Görüntüler 50X büyütmede elde edilmiştir.

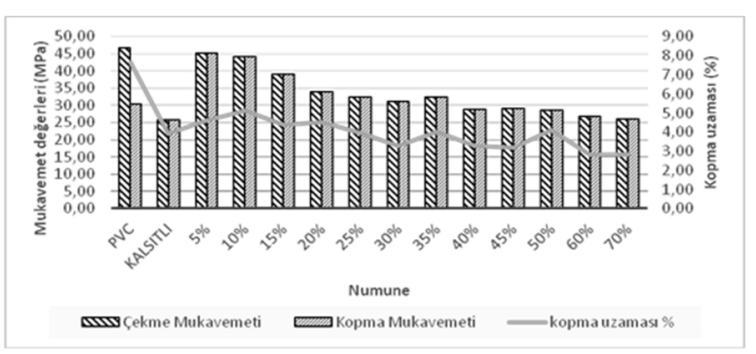

Şekil 4. Farklı PVC kompozitler için çekme, kopma mukavemeti ve kopma uzaması sonuçları (Results of the tensile and break strength and the elongation at break (\%) for different PVC composites)
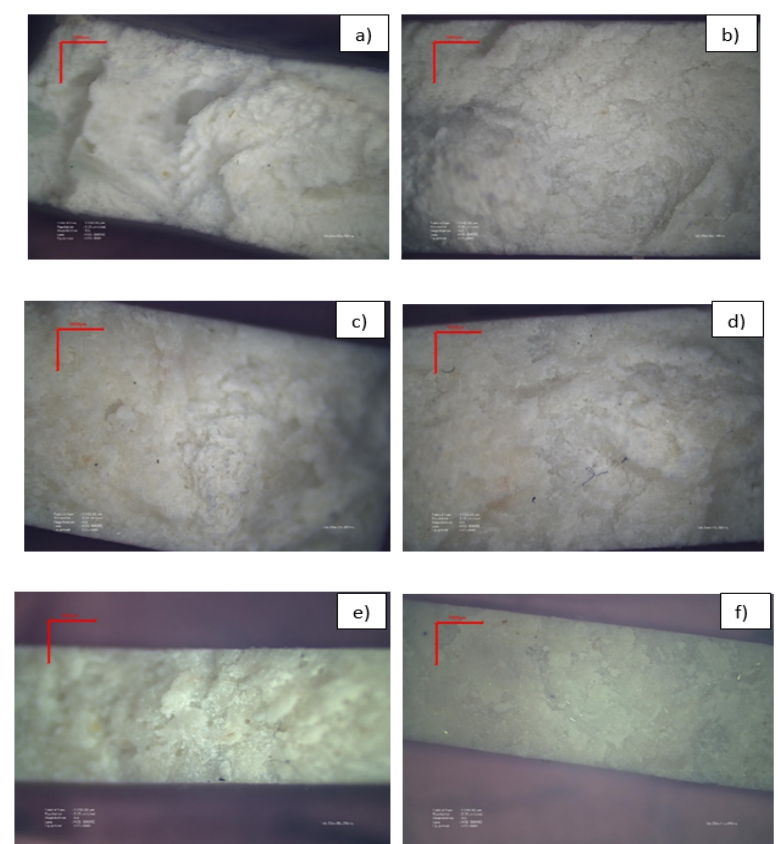

Şekil 5. Farklı numunelerde optik mikroskop kırık yüzey görüntüleri; a) Saf PVC, b) Kalsit dolgulu PVC, c) $\% 5$ atık katk1lı PVC kompozit, d) \%10 atık katkılı PVC kompozit, e) \%15 atık katk1lı PVC kompozit, f) \%35 atık katkılı PVC kompozit (Fractured surface images of pure PVC (a), calcite reinforced of PVC (b), 5 $\mathrm{wt} \%$ waste reinforced $\mathrm{PVC}$ composite (c), $10 \mathrm{wt} \%$ waste reinforced PVC composite (d) $15 \mathrm{wt} \%$ waste reinforced PVC composite (e), $35 \mathrm{wt} \%$ waste reinforced $\mathrm{PVC}$ composite (f)) 
Tüm numunelerde sünek kırılma olduğu görülmektedir. Ayrıca atık katkılı numunelerde cam fiberler parlak görülmektedir. Yüksek çekme mukavemetine sahip olan Saf PVC, kalsit dolgulu PVC ve \%5-\%10-\%15 ve \%35 kesme atığ1 katk1lı numunelerin kırık yüzeylerinden alınan SEM görüntüleri Şekil 6' de verilmiştir. Tüm numuneler 250X büyütmede çekilmiştir.
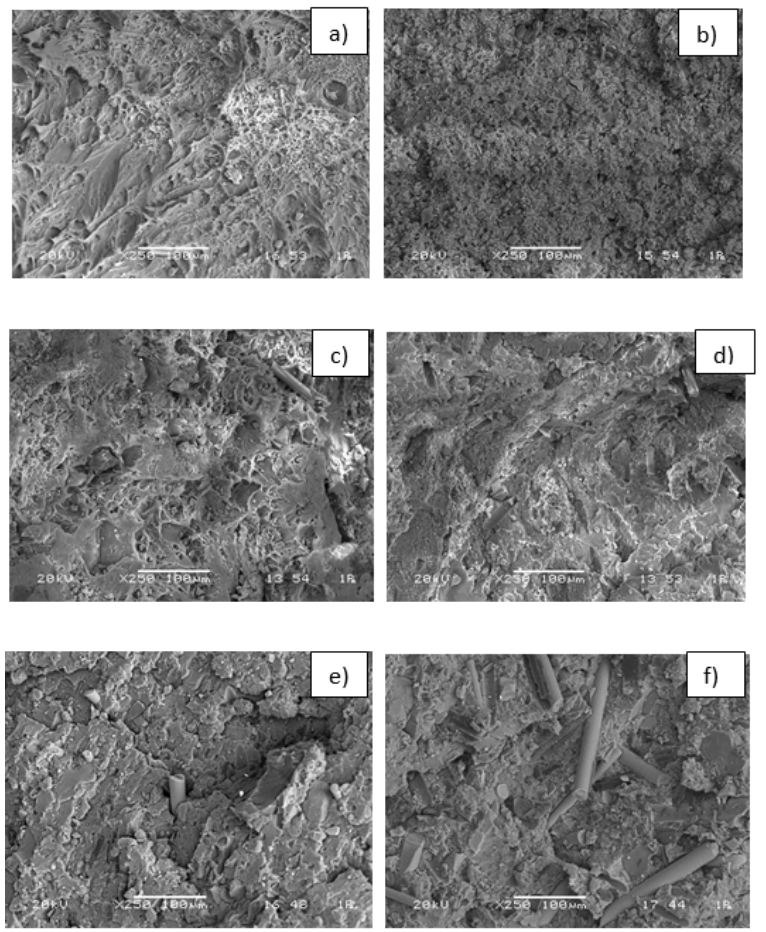

Şekil 6. Farklı numunelerde taramalı elektron mikroskobu (SEM) kırık yüzey görüntüleri; a) Saf PVC, b) Kalsit dolgulu PVC, c) $\% 5$ atık katkılı PVC kompozit, d) \%10 atık katkılı PVC kompozit, e) \%15 atık katkılı PVC kompozit, f)\%35 atık katkılı PVC kompozit (Fractured surface images of pure PVC (a), calcite reinforced of PVC (b), $5 \mathrm{wt} \%$ waste reinforced PVC composite (c), $10 \mathrm{wt} \%$ waste reinforced PVC composite (d) $15 \mathrm{wt} \%$ waste reinforced PVC composite (e), $35 \mathrm{wt} \%$ waste reinforced PVC composite (f))

PVC, kalsit katkılı, \%5, \%10, \%15 ve $\% 35$ atık katkılı numunelerin kırık yüzey SEM görüntüleri alınmıştır. PVC numunenin sünek kırılma gösterdiği net bir biçimde görülmüştür. Atık katkısı oranı arttıkça cam fiber oranının arttığı gözlemlenmiştir. Ayrıca görüntülerde cam fiber ve $\mathrm{SiO}_{2}$ partiküllerin matrisle uyumlu olduğu görülmektedir.

\section{6 Üç Nokta Ĕgme Deneyi (Three Point Flexural Experiment)}

Kalsit, farklı oranlarda kesme atığı içeren PVC matrisli kompozitlerin ve saf PVC numunenin üç nokta eğme deneyi sonucunda elde edilen çekme mukavemeti ve kopma uzaması değerleri Şekil 7'de verilmektedir. Standarda göre üç nokta eğme testinde kopma uzaması \%5' e geldiğinde test bitmektedir. Sadece \%40-\%45-\%50-\%60-\%70 at1k katk1l numuneler $\% 5$ uzamaya gelmeden kopmaya uğramışlardır. En yüksek çekme mukavemeti \%35 atık katkılı numunede görülmüştür. En düşük çekme mukavemeti ise kalsit katkılı numunede görülmüştür.

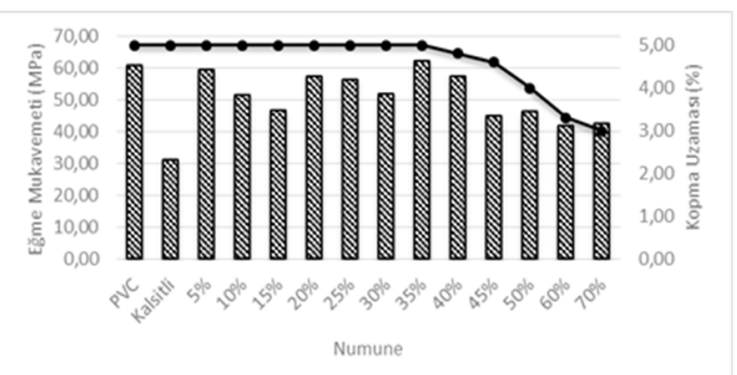

Şekil 7. Farklı PVC kompozitler için üç nokta eğme deneyi sonuçları (Results of the three point flexural test for different PVC composites)

\subsection{Darbe Deneyi (Impact Experiment)}

Kalsit, farklı oranlarda kesme atığı içeren PVC matrisli kompozitlerin ve saf PVC numunenin darbe deney sonuçları J/m Şekil 8'de verilmektedir.

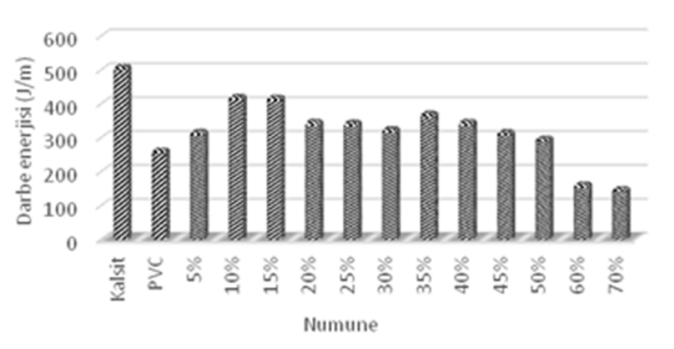

Şekil 8. Farklı PVC kompozitler darbe deneyi sonuçları (Results of the impact test for different PVC composites)

En yüksek kırılma enerjisi kalsit katkılı numunede görülmüştür. Atık katkılı numunelerin kırılma enerjisi PVC numuneye göre yüksek çıkmıştır. Zeng ve arkadaşları kalsit katkısı ile PVC darbe dayanımının arttırdığını bulmuşlardır [27].

\subsection{DTA-TG Analizi (DTA-TG Analysis)}

Saf PVC numunenin DTA-TG analizi Şekil 9'da verilmektedir. Farklı oranlarda kesme atığı içeren PVC matrisli kompozitlerin DTA-TG analiz sonuçları benzer çıkmıştır. Kalsit katkılı numunenin DTA-TG analizi ise Şekil 10'te verilmektedir. $\% 5, \% 35$ ve $\% 70$ katkılı numunelerin DTA-TG analizleri Şekil 11-13 arasında verilmektedir. Şekil 9'daki grafikte görüldüğü gibi $300^{\circ} \mathrm{C}$ ve $350^{\circ} \mathrm{C}$ civarında endotermik reaksiyon ve ani ağırlık kaybı meydana gelmiştir. \%55,9 ağırlık kaybı oluşmuştur. Araştırmalara göre bu reaksiyon ve ağırlık kaybı PVC prolizi ile açıklanabilmektedir. PVC bozunması sonucu $\mathrm{HCl}$ gazı ve Metan $\left(\mathrm{CH}_{4}\right)$, benzen $\left(\mathrm{C}_{6} \mathrm{H}_{6}\right), \mathrm{CO}, \mathrm{CO}_{2}, \mathrm{H}_{2} \mathrm{O}$, etan $\left(\mathrm{C}_{2} \mathrm{H}_{6}\right)$, eten $\left(\mathrm{C}_{2} \mathrm{H}_{4}\right)$, stiren $\left(\mathrm{C}_{8} \mathrm{H}_{8}\right)$, toluen $\left(\mathrm{C}_{7} \mathrm{H}_{8}\right)$ ve propen $\left(\mathrm{C}_{3} \mathrm{H}_{6}\right)$, önemli miktarlarda açığa çıktığı 
söylenebilmektedir. $490^{\circ} \mathrm{C}$ ve $550^{\circ} \mathrm{C}$ civarında oluşan ekzotermik reaksiyonu ise yanma reaksiyonu olduğu düşünülmektedir [28-33]. \%19,7 ağırlık kaybı oluşmuştur.

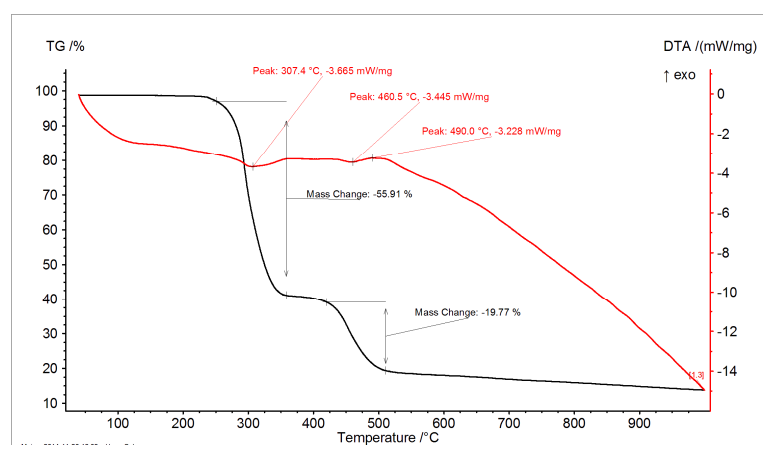

Şekil 9. Saf PVC numunenin DTA-TG analizi sonuç grafiği (DTA-TG analysis of pure PVC)

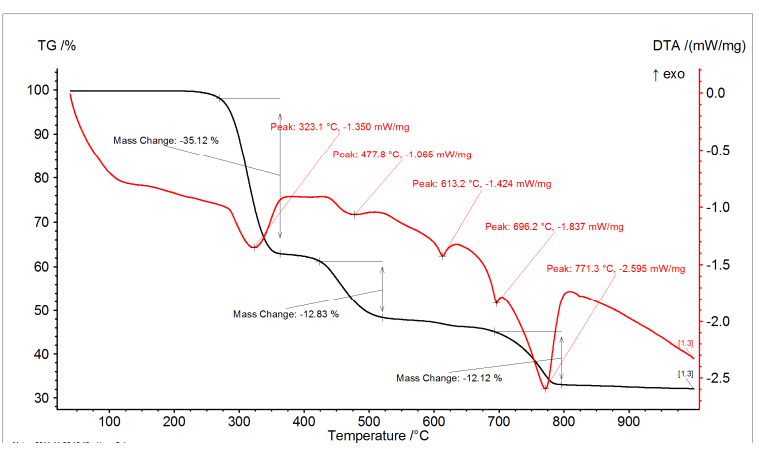

Şekil 10. Kalsit katkılı PVC numunenin DTA-TG analizi sonuç grafiği (DTA-TG analysis of calcite reinforced of PVC)

Şekil $10^{\prime}$ da görüldüğü gibi $260^{\circ} \mathrm{C}$ ve $370^{\circ} \mathrm{C}$ civarında endotermik reaksiyon ve ani ağırlık kaybı meydana gelmiştir. \%35,1 ağırlık kaybı oluşmuştur. Ağırlık kaybının saf PVC'ye oranla daha düşük olduğu gözlemlenmiştir. Bunun sebebinin kalsit katkısı olduğu düşünülmektedir. Araştırmalara göre bu reaksiyon ve ağırlık kaybı PVC prolizi ile açıklanabilmektedir. PVC bozunması sonucu $\mathrm{HCl}$ gazı ve Metan $\left(\mathrm{CH}_{4}\right)$, benzen $\left(\mathrm{C}_{6} \mathrm{H}_{6}\right), \mathrm{CO}, \mathrm{CO}_{2}, \mathrm{H}_{2} \mathrm{O}$, etan $\left(\mathrm{C}_{2} \mathrm{H}_{6}\right)$, eten $\left(\mathrm{C}_{2} \mathrm{H}_{4}\right)$, stiren $\left(\mathrm{C}_{8} \mathrm{H}_{8}\right)$, toluen $\left(\mathrm{C}_{7} \mathrm{H}_{8}\right)$ ve propen $\left(\mathrm{C}_{3} \mathrm{H}_{6}\right)$, önemli miktarlarda açığa çıktığ söylenebilmektedir. $470^{\circ} \mathrm{C}$ ve $510^{\circ} \mathrm{C}$ civarında oluşan ekzotermik reaksiyonu ise yanma reaksiyonu olduğu düşünülmektedir [28-33]. \%12,83 ağırlık kaybı oluşmuştur ve kalsit katkısının yanma sonucu oluşan ağırlık kaybını azalttığı görülmektedir. Kalsit katkısı olduğu için $610-690^{\circ} \mathrm{C}$ civarında oluşan endotermik reaksiyonun bağıl nemin bünyeden uzaklaştığ düşünülmektedir. $800^{\circ} \mathrm{C}$ civarında oluşan endotermik reaksiyonun ise kalsinasyon reaksiyonu olduğu düşünülmektedir. \%12,12 kadar ağırlı kaybı oluşmuştur. Ağırlık kaybının ise $\mathrm{CO}_{2}$ çıkışından olduğu düşünülmektedir [34]. Şekil 11-13 arasında görüldüğü gibi $290^{\circ} \mathrm{C}$ ile $380^{\circ} \mathrm{C}$ arasında endotermik reaksiyon ve ani ağırlık kaybı meydana gelmiştir. Şekil 11'deki ağırlık kaybı \%56,8 olarak bulunmuştur. Şekil 12 'teki ağırlık kaybı \%44,9 olarak bulunmuştur. Şekil 13'teki ağırlık kaybı ise \%36,74 olarak bulunmuştur. Sonuçlara göre atık katkısı arttıkça $290^{\circ} \mathrm{C}$ ve $380^{\circ} \mathrm{C}$ civarında oluşan ağırlık kaybı azalmaktadır. $490^{\circ} \mathrm{C}$ ve $560^{\circ} \mathrm{C}$ civarında oluşan ekzotermik reaksiyonu ise yanma reaksiyonu olduğu düşünülmektedir [28-33].

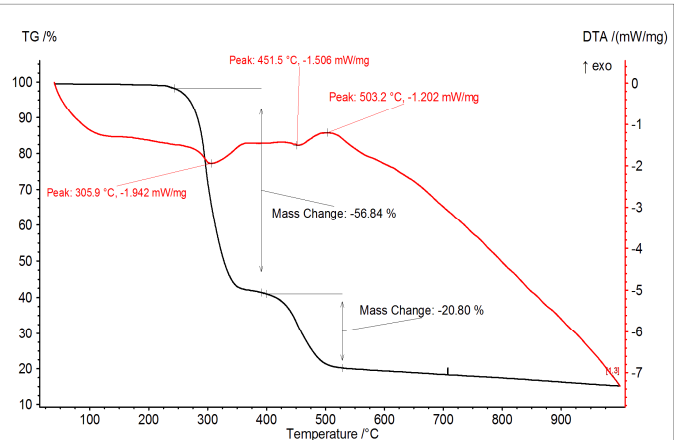

Şekil 11. $\% 5$ atık katkılı PVC kompozit numunenin DTA-TG analizi sonuç grafiği (DTA-TG analaysis of 5 wt $\%$ waste reinforced $\mathrm{PVC}$ composite)

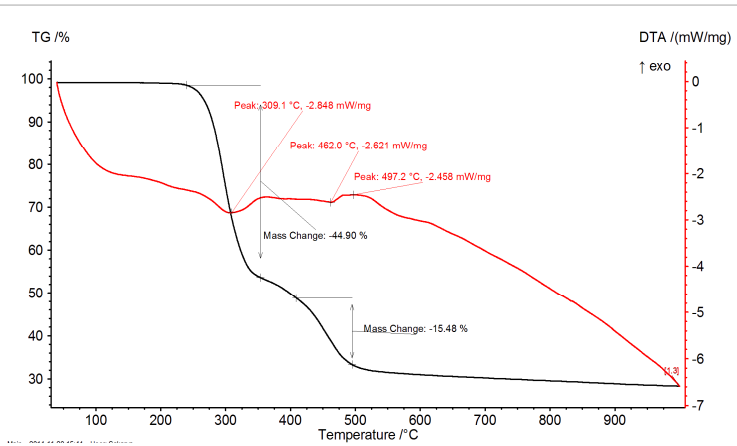

Şekil 12. \%35 atık katkıll PVC kompozit numunenin DTA-TG analizi sonuç grafiği (DTA-TG analaysis of 35 wt $\%$ waste reinforced $\mathrm{PVC}$ composite)

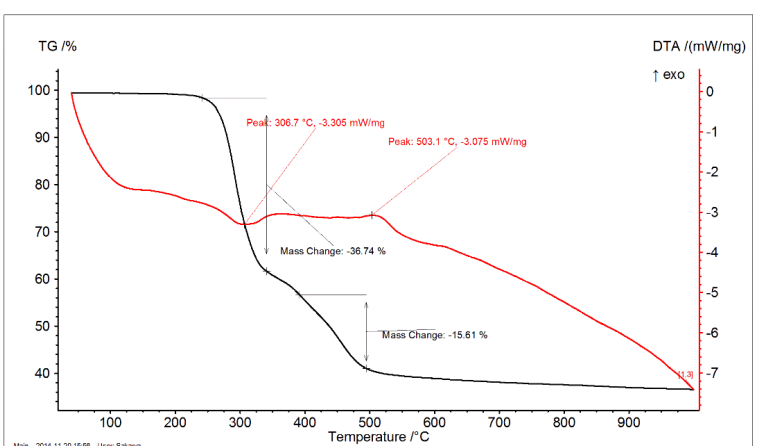

Şekil 13. $\% 70$ atık katkılı PVC kompozit numunenin DTA-TG analizi sonuç grafiği (DTA-TG analaysis of 70 wt $\%$ waste reinforced $\mathrm{PVC}$ composite)

$\% 5$ atık katkılı numunedeki bu sıcaklıklar arasındaki ağırlık kaybı \%20,8 olup saf PVC ile benzer ağırlık kaybına uğramıştır. \%35 atık katkılı numune \%15,4 ve $\% 70$ atık katkılı numune ise $\% 15,6$ ağırlık kaybına uğramıştır. Atık katkısının yanma sonucu oluşan ağırlık kaybını $\% 5$ oranında azalttığı görülmektedir. Saf, kalsit ve atık katkılı PVC numunelere ait sıcaklık-ağırlık değişimi değerleri Tablo 1' de verilmektedir. 
Tablo 1. Sıcaklık-ağırlık değişimi (Temperature and mass change)

\begin{tabular}{|c|c|c|}
\hline $\begin{array}{l}\text { Numune } \\
\text { (sample) }\end{array}$ & $\begin{array}{c}290-380{ }^{\circ} \mathrm{C} \\
\text { kütle kaybı } \\
\text { (mass change) }\end{array}$ & $\begin{array}{c}490-560{ }^{\circ} \mathrm{C} \\
\text { kütle kaybı } \\
\text { (mass change) }\end{array}$ \\
\hline $\begin{array}{c}\text { Saf PVC } \\
\text { (Pure PVC) }\end{array}$ & $\% 55,9$ & $\% 19,7$ \\
\hline $\begin{array}{l}\text { Kalsit katkılı } \\
\text { PVC (Calcite } \\
\text { reinforced of } \\
\text { PVC) }\end{array}$ & $\% 35,1$ & $\% 12,8$ \\
\hline $\begin{array}{l}\% 5 \text { atık katkılı } \\
\text { (5 wt\% waste } \\
\text { reinforced) }\end{array}$ & $\% 56,8$ & $\% 20,8$ \\
\hline $\begin{array}{c}\% 35 \text { atık } \\
\text { katkılı } \\
\text { (35 wt\% waste } \\
\text { reinforced) }\end{array}$ & $\% 44,9$ & $\% 15,4$ \\
\hline $\begin{array}{c}\% 70 \text { atık } \\
\text { katk1lı } \\
\text { (70 wt\% waste } \\
\text { reinforced) }\end{array}$ & $\% 36,7$ & $\% 15,6$ \\
\hline
\end{tabular}

\section{SONUÇLAR (CONCLUSIONS)}

Atık katkısı ile üretilen numunelerin yoğunluğu kalsit dolgusu ile üretilen numunelerin yoğunluğundan daha düşüktür. Buna bağlı olarak aynı miktarda hammadde ile daha uzun metrajlı üretim gerçekleştirilebileceği öngörülmüştür. En yüksek sertlik değerleri \%35 ve $\%$ atık katkılı numunelerde görülmüştür. Kalsit katkılı numunenin sertlik değeri düşük çıkmıştır. En düşük çekme ve kopma mukavemeti kalsit katkılı numunede görülmüştür. Fiyat performans oranı düşünüldüğünde çekme ve kopma mukavemeti uygun olan katkı oranının \%35 olduğu öngörülmüştür.

Üç nokta eğme testinde en yüksek çekme mukavemeti $\% 35$ atık katkılı numunede görülmüştür ve $\% 5$ kopma uzamasına geldiğinde hâlâ kopma gözlemlenmemiştir. En düşük çekme mukavemeti ise kalsit katkılı numunede görülmüştür. Darbe testine göre en yüksek kırılma enerjisi kalsit katkılı numunede görülmüştür. Atık katkılı numuneler arasında fiyat performans oranı düşünüldüğünde en uygun değerin \%35 atık katkılı numune olduğu görülmüştür. Kullanılan atığın İzaydaş tarafindan bertaraf maliyeti $815 \mathrm{TL} /$ ton olarak belirlenmiştir [35]. Laboratuvar şartlarında atık 624 TL/ton maliyetle kurutulmuştur. Fabrika şartlarına uygun büyük kurutucular ile daha düşük maliyetle atığın kurutulması araştırılmalıdır.

\section{TEŞEKKÜR (ACKNOWLEDGMENT)}

Yazarlar aldıkları destekten ötürü Sanayi Tezleri Programı (SAN-TEZ) 0116.STZ.2013-1 numaralı proje kapsamında Türkiye Cumhuriyeti Bilim, Sanayi ve Teknoloji Bakanlığı' na, Subor Boru San. ve Tic. A.Ş.' ne ve Sakarya Üniversitesi' ne teşekkür eder.

\section{KAYNAKLAR (REFERENCES)}

1. Bekhet, N.E., "Tribological Behavior of Drawn Polypropylene", Wear, Cilt 236, No 1-2, 55-61, 1999.

2. Mann, D., Automotive Plastics ve Composites Worldwide Markets and Trends to 2007, Elsevier, New York, A.B.D., 1999.

3. Zweifel, H. ve Amos, E., Plastics Additives Handbook, Hanser, Ohio, A.B.D., 2001.

4. Kaya, F., Ana Hatlarıyla Plastikler ve Katkı Maddeleri, Birsen Yayınevi, İstanbul, Türkiye, 2005.

5. Nass L., Encyclopedia of PVC, Second Edition: Compounding Processes, Product Design and Specifications, CRC Press, New York, A.B.D., 1992.

6. Ambrogi, V., Brostow, W., Carfagna, C., Pannico, M., ve Persico, P., "Plasticizer Migration From Cross-Linked Flexible PVC: Effects on Tribology And Hardness", Polymer Engineering ve Science, Cilt 52, No 1, 211-217, 2012.

7. Cowley, W. E., "Design Aspects of Butt Welded Thermoplastic Pipes", International Journal of Materials in Engineering Applications, Cilt 1, No 6, 323-327, 1979.

8. Balkaya, M. Sağlamer, A. ve Moore, I. D. "Conta Bağlantılı PVC Boruların Deformasyon Davranışının Laboratuvar Deneyleri İle Belirlenmesi”, İTü Dergisi, Cilt 10, No 4, 153162, 2012.

9. Tanoğlu, $M$. ve Toğulga, M. "Kompozit malzemeler ve jeotermal uygulamaları", Jeotermal Enerji Semineri, Tepekule Kongre ve Sergi Merkezi, İzmir, 407-419, 23-25 Kasım 2005.

10. Weidenfeller, B. "Internal Friction Studies of Particulate Filled Polypropylene", Materials Science and Engineering: A, Cilt 442, No 1, 371-374, 2006.

11. Chen, N. Wan ve C. Zhang, Y. "Effect of Nano$\mathrm{CaCO}_{3}$ on Mechanical Properties of PVC and PVC/Blendexblend", PolymerTesting, Cilt 23, 169-174, 2003.

12. Bryant, W. S. ve Wiebking, H. E. "The Effect of Calcium Carbonate Size and Loading Level on the Impact Performance of Rigid PVC Compounds Containing Varying Amounts of Acrylic Impact Modifier", ANTEC Conference Proceedings, San Francisco, CA, 1-5, 5-9 Mayıs 2002.

13. Rothon, N. Particulate Fillers for Polymers, iSmithers Rapra Publishing, Shropshire, United Kingdom, 2001.

14. Zhu, A., Shi, Z., Cai, A., Zhao, F. ve Liao, T. "Synthesis of Coreshell $\mathrm{PMMA} / \mathrm{SiO}_{2}$ Nanoparticles With Suspension Dispersion Polymerization in an Aqueous System and its Effect on Mechanical Properties of PVC 
Composites", Polymer Testing, Cilt 27, No 5, 540-547, 2008.

15. Asokan, P., Mohamed O. ve Andrew P., "Assessing the Recycling Potential of Glass Fibre Reinforced Plastic Waste in Concrete and Cement Composites", Journal of Cleaner Production Cilt 17, No 9, 821-829, 2009.

16. Katz, H. S. ve Mileski, J. V. Handbook of fillers for plastics, Springer Science and Business Media, New York, A.B.D., 1987.

17. ASTM D6980 - 12, Standard Test Method for Determination of Moisture in Plastics by Loss in Weight, 2012.

18. Marghitu, D. B. Mechanical Engineer's Handbook, Academic Press, New York, A.B.D., 2001.

19. ASTM D792, Standard Test Methods for Density and Specific Gravity (Relative Density) of Plastics by Displacement, 2013.

20. ASTM D2240, "Standard Test Method for Rubber Property Durometer Hardness Shore Hardness, 2010.

21. Stuart, B. H. Polymer Analysis, John Wiley and Sons., New York, A.B.D., 210-227, 2008

22. ASTM D638, Standard Test Method for Tensile Properties of Plastics, 2014.

23. ASTM D 790, Standard Test Methods for Flexural Properties of Unreinforced and Reinforced Plastics and Electrical Insulating Materials, 2010.

24. ASTM D4812, Standard Test Method for Unnotched Cantilever Beam Impact Resistance of Plastics, 2012.

25. Mengeloglu, F. ve Matuana, L. M. "Mechanical Properties of Extrusion-Foamed Rigid PVC/Wood-Flour Composites", Journal of Vinyl and Additive Technology, Cilt 9, No 1, 26-31, 2003.

26. Chen, C. H., Li, H. C., Teng, C. C., ve Yang, C. H. "Fusion, Electrical Conductivity, Thermal, and Mechanical Properties of Rigid Poly (Vinyl Chloride) (PVC) / Carbon Black (CB)
Composites", Journal of Applied Polymer Science, Cilt 99, No 5, 2167-2173, 2006.

27. Zeng, X. F., Wang, W. Y., Wang, G. Q. ve Chen, J. F., "Influence of The Diameter of $\mathrm{CaCO}_{3}$ Particles on the Mechanical and Rheological Properties of PVC Composites", Journal of Materials Science, Cilt 43, No 10, 3505-3509, 2008.

28. Avci, A. E., Analysis of UV Induced Dehydrochlorinated PVC, Doctoral Dissertation, Bilkent University, Department of Chemistry and The Institute of Engineering and Science, Ankara, Turkey, 2003.

29. L. Nass, Encyclopedia of PVC, Second Edition: Compounding Processes, Product Design and Specifications, CRC Press, New York, A.B.D., 1992.

30. L. Gye-Seung., "Recycling EAF Dust by Heat Treatment with PVC", Minerals Engineering, Cilt 20, No 8, 739-746, 2007.

31. Saeed, L., "Pyrolysis and Combustion of PVC, PVC-Wood and PVC-Coal Mixtures in a TwoStage Fluidized Bed Process", Fuel Processing Technology, Cilt 85, No 14, 1565-1583, 2004.

32. Cazes, J., Analytical Instrumentation Handbook, Boca Raton, CRC Press, A.B.D., 2004.

33. McKinney, P. V., "DTA Evidence for Physical Orientation (Crystallinity) in PVC", Journal of Applied Polymer Science, Cilt 11, No 7, 11891197, 1967.

34. Centeno, M. A., "Thermal Analysis of Monument Patina Containing Hydrated Calcium Oxalates", Thermochimica Acta, Cilt 512, No 1, 5-12, 2011.

35. İnternet: Atık Yönetim Sistemleri İçin Yatırım ve İşletim Maliyetleri ve Çeşitli Atık Türleri için Aritim Fiyatlar1, http://atanafs.com/images/stories/download/Atik Yonetim_Sistemleri_icin_Yatirim_ve sletim_Ma liyetleri_ve_Cesitli_Atik_Turleri_icin_Aritim_Fi yatlari.pdf.pdf, $201 \overline{5}$. 